UNIVERSIDADE DE SÃO PAULO

FFCLRP - DEPARTAMENTO DE BIOLOGIA

PROGRAMA DE PÓS-GRADUAÇÃO EM CIÊNCIAS

ÁREA BIOLOGIA COMPARADA

\title{
Padrão de ocupação e seleção de conchas pelo ermitão Paguristes tortugae SCHMITT, 1933 \\ (Crustacea, Anomura) na llha Anchieta, Ubatuba, São Paulo
}

\section{LAURA CRISTINA DA CRUZ DOMICIANO}

\author{
Dissertação apresentada à \\ Faculdade de Filosofia, Ciências e \\ Letras de Ribeirão Preto da USP, \\ como parte das exigências para a \\ obtenção do título de Mestre em \\ Ciências, área: Biologia Comparada.
}

Ribeirão Preto - SP

2001 
UNIVERSIDADE DE SÃO PAULO

FFCLRP - DEPARTAMENTO DE BIOLOGIA

PROGRAMA DE PÓS-GRADUAÇÃO EM CIÊNCIAS

ÁREA BIOLOGIA COMPARADA

\section{Padrão de ocupação e seleção de conchas pelo ermitão Paguristes tortugae SCHMITT, 1933 \\ (Crustacea, Anomura) na llha Anchieta, Ubatuba, São Paulo}

\section{LAURA CRISTINA DA CRUZ DOMICIANO}

Orientador: Prof. Dr. Fernando Luis Medina Mantelatto

Dissertação apresentada à
Faculdade de Filosofia, Ciências e
Letras de Ribeirão Preto da USP,
como parte das exigências para a
obtenção do título de Mestre em
Ciências, área: Biologia Comparada.

Ribeirão Preto - SP

2001 
Domiciano, L. C. C.

"Padrão de ocupação e seleção de conchas pelo ermitão Paguristes tortugae Schmitt, 1933 (Crustacea, Anomura) na Ilha Anchieta, Ubatuba, São Paulo"

$$
\mathrm{v}+108 \mathrm{p}
$$

Dissertação apresentada à Faculdade de Filosofia, Ciências e Letras de Ribeirão Preto da USP, como parte das exigências para a obtenção do título de Mestre em Ciências, área Biologia Comparada.

Orientador: Mantelatto, F. L. M.

1. ANOMURA 2. CONCHA 3. CRUSTACEA 4. ERMITÃO 4. SELEÇÃO 
"Quando amamos e acreditamos do fundo de nossa alma em algo, nos sentimos mais fortes que o mundo e somos tomados de uma serenidade que vem da certeza de que nada poderá vencer nossa fé.

Essa força estranha, faz com que sempre tomemos as decisões certas na hora exata e, quando atingimos nosso objetivo ficamos surpresos com a nossa própria capacidade"

\section{PAULO COELHO}

Paguristes tortugae SCHMITT, 1933 
A paciência é a porta para a compreensão de tudo $A$ renovação das atitudes, consiste em despertar interesses nunca antes percebidos

A melhor forma que encontrei de ver a vida, foi descrevendo-a.

(a autora)

Dedico este trabalho aos meus queridos pais e à minha irmã Sílvia, por todo o carinho, incentivo e amor. 


\section{AGRADECIMENTOS}

A realização deste trabalho foi fruto de muito esforço e de uma gratificante caminhada que se concretiza em mais um degrau vencido, o qual não teria sido possivel sem a assistência de um grupo de pessoas talentosas, generosas e profissionais.

Agradeço ao Prof. Dr. Fernando Luis Medina Mantelatto, por ter confiado na minha capacidade, pelo apoio, dedicação e incentivo que me fizeram crescer cientificamente. Às cuidadosas revisões e valiosas sugestões que tanto contribuíram para a realização deste trabalho e por ter me ensinado que os vencedores da batalha da vida são homens perseverantes que, sem se julgarem gênios, se convenceram que só pela perseverança e esforço, poderiam chegar ao fim almejado. Sua orientação não se resume somente a esse trabalho, mas ecoará por toda a minha vida.

Agradeço aos meus pais, Luis Carlos e Maria Aparecida, por me apoiarem nessa caminhada e me ensinarem a lutar contra os obstáculos, sendo meu espelho de dignidade e perseverança. À minha irmã Sílvia e ao meu primo Edson pelo carinho e incentivo de sempre.

À CAPES (Coordenação de Aperfeiçoamento de Pessoal de Nivel Superior) pelo auxílio financeiro concedido, o qual foi de suma importância para a realização deste trabalho.

Agradeço à FAPESP (Fundação de Amparo à Pesquisa do Estado de São Paulo) processo $n^{\circ}$ 98/07454-5, pelo custeio das despesas de coleta durante este trabalho, sob a coordenação do Prof. Mantelatto.

Agradeço à Secretaria do Meio Ambiente do Estado de São Paulo, IBAMA e ao Parque Estadual da ITha Anchieta (Proc. n $42358 / 98$ ) pelas permissões e facilidades oferecidas durante a realização deste trabalho. 
Ao Curso de Pós-Graduação em Biologia Comparada desta faculdade, pela oportunidade de formação durante a realização deste trabalho.

À amiga e colega de trabalho Renata B. Garcia, minha gratidão não só pela sua competência profissional e paciência que teve em me ensinar, a qual tanto contribuiu neste trabalho, mas também pelas particularidades em nossos momentos de descontração. Agradeço também por me permitir fazer uso da metodologia de laboratório desenvolvida em seu mestrado.

Ao Prof. Mantelatto, à Jussara Martinelli e à Renata B. Garcia pelas coletas de $P$. tortugae, as quais me permitiram realizar este trabalho; ao Leandro M. Sousa e à Vera F. Alarcon pela ajuda em laboratório na análise de P. tortugae.

Agradeço à Andrea L. Meireles e ao Ronaldo A. Christofoletti pela contribuição nas coletas de ermitões para os experimentos em laboratório. Ao Ronaldo, em especial pela assessoria computacional, que tanto colaboraram para o desenvolvimento deste trabalho.

Aos amigos e colegas de laboratório, Andrea, Carmen, Fabiola, Leandro, Renata, Ronaldo e Vera pela amizade, respeito e pelos bons momentos que passamos juntos. Cada um sabe o quão importante foram e são para mim.

Ao Prof. Dr. Wagner Eustáquio de Paiva Avelar pelo uso do estereomicroscópio óptico para mensurar os animais.

Agradeço ao $\mathcal{D}$ r. Nilton Hebling e ao Dr. Osmar Domaneschi pela identificação dos ermitões e das conchas, respectivamente.

Agradeço ao Alexandre e à Virgínia pela hospedagem em Ubatuba.

À Adriana Morales e Edmara Gonçalves pela amizade e contribuição no ingresso de meu mestrado.

Às amigas Adna, Ana Lúcia, Cínthia, Deborah, Estela, Fernanda, Geórgia, Karina, Márcia, Rosiane e Samanta pela verdadeira amizade, estando sempre ao meu lado, torcendo para que tudo saísse bem. "Quem tem um amigo, 
mesmo que um só, jamais sofrerá de solidão, pode morrer de saudades, mas nunca estará só" (Amir Klink).

À D. Maria Joaquina pelos conselhos e incentivos.

$\mathrm{E}$, finalmente, à todos aqueles, que direta ou indiretamente, contribuíram para a realização deste trabalho, o meu muito obrigada e, peço desculpas se esqueci de mencionar alguém. 
Página

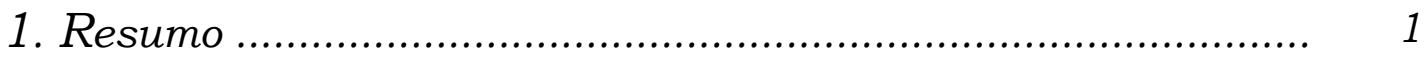

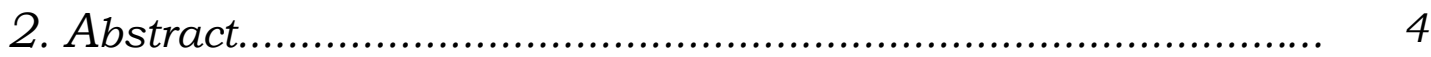

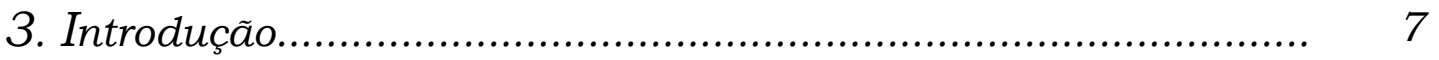

3.1 Caracterização dos Anomura........................................ 8

3.2 Relação com a Concha................................................. 10

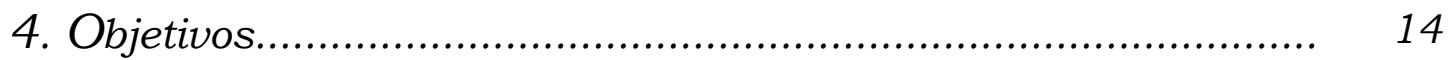

5. Material \& Métodos................................................................ 16

5.1 Caracterização da Espécie em estudo.......................... 17

5.2 Caracterização da Área de estudo................................ 18

5.3 Metodologia de Coleta................................................. 19

5.4 Aspectos Analisados.................................................. 20

5.4.1 Ermitões................................................... 21

5.4.2 Conchas.................................................. 22

5.5 Ocupação das Conchas............................................... 22

5.6 Seleção das Conchas em Laboratório........................... 23

5.6.1 Seleção do Tipo de Concha............................ 24

5.6.2 Seleção do Tamanho da Concha.................... 25

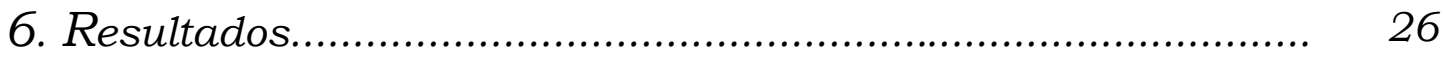


6.1 Aspectos Populacionais dos Ermitões.......................... 27

6.2 Fatores Abióticos............................................................. 31

6.3 Ocorrência e Ocupação de Conchas............................... 32

6.4 Padrão de Preferência de Conchas................................ 50

6.4.1 Seleção dos Tipos de Conchas....................... 51

6.4.2 Seleção pelo Tamanho das Conchas............... 60

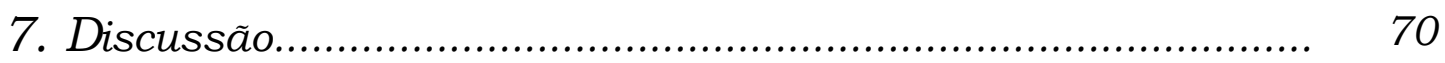

7.1 Aspectos Populacionais dos Ermitões.......................... 71

7.2 Utilização das Conchas.................................................

7.2.1 No Ambiente................................................... $\quad 74$

7.2.2 No Laboratório................................................. 84

8. Referências Bibliográficas...................................................... 89

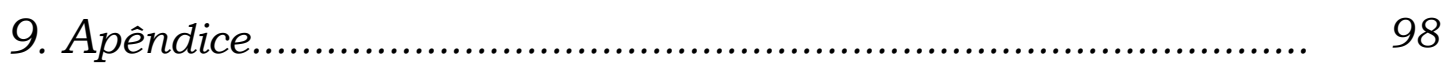


No presente trabalho caracterizou-se o padrão de utilização de conchas pelo ermitão Paguristes tortugae, habitante do infralitoral da Ilha Anchieta (Ubatuba), analisando-se comparativamente o padrão de seleção e de ocupação de conchas no ambiente natural e em laboratório.

Para o estudo de ocupação de conchas no ambiente, os indivíduos foram coletados mensalmente (janeiro a dezembro/1998) na região infralitorânea de quatro áreas da Ilha, por mergulho autônomo. Os ermitões foram medidos quanto ao comprimento e largura do escudo cefalotorácico, altura e comprimento do própodo quelar, contados, determinado seu sexo e pesados. Para os experimentos de seleção de conchas, os animais foram mantidos vivos em aquário de vidro. Nestes experimentos laboratoriais, os animais foram retirados de suas conchas e colocados com um número suficiente de conchas com tamanhos apropriados. Após $72 \mathrm{~h}$ os animais e as conchas escolhidas foram analisados quanto ao peso dos ermitões e das conchas e as respectivas medidas. A escolha quanto ao tipo de concha foi analisada de acordo com a porcentagem de ocupação de uma espécie em relação à outra. Para a escolha quanto ao tamanho da concha, avaliou-se as análises de regressão entre as dimensões dos ermitões e das conchas.

Um total de 2429 exemplares de $P$. tortugae foram analisados (1092 machos, 495 fêmeas não-ovígeras e 842 fêmeas ovígeras), ocupando 21 espécies de conchas de gastrópodos. Este perfil, indicativo de ampla diversidade no padrão de ocupação, apresentou Pisania auritula (35.49\%), Cerithium atratum (27.83\%) e Morula nodulosa (12.70\%) como as mais ocupadas. Os machos (38.46\%) e as fêmeas ovígeras (38.00\%) ocuparam, em maior porcentagem, as conchas de P. auritula, enquanto que as fêmeas não-ovígeras (39.40\%) ocuparam C. atratum. Houve dimorfismo sexual quanto ao tamanho em favor dos machos e, a razão sexual foi de 1:1.2, em favor das fêmeas. Verificou-se que as conchas mais ocupadas foram as menos adequadas. Leucozonia nassa foi a mais adequada tanto no ambiente quanto no laboratório, corroborando a 
hipótese de que a ocupação das conchas está associada ao ambiente em que vivem e à sua disponibilidade. A maior correlação ocorreu entre as dimensões dos ermitões e o peso da concha, sendo esta a relação que melhor caracterizou a escolha e a ocupação das conchas por P. tortugae. Quanto ao sexo, as fêmeas ovígeras apresentaram as melhores correlações, estando melhor adequadas ao peso e ao volume interno da concha, favorecendo a fecundidade e o processo reprodutivo anual. Tal condição foi corroborada com os experimentos de laboratório, onde constatou-se que as fêmeas ovígeras apresentaram preferência por conchas com maior volume interno (L. nassa e C. atratum). Em laboratório, dentre as seis espécies de conchas com maior ocorrência de ocupação no ambiente, o padrão de preferência foi $L$. nassa > P. auritula $>$ S. haemastoma > T. viridula para os individuos maiores e C. atratum > M. nodulosa para os indivíduos menores. Estes resultados, comparados aos da natureza, demonstraram que $P$. tortugae apresentou um padrão de preferência pelas conchas mais disponiveis na natureza, mesmo não sendo as mais adequadas quanto às dimensões. Neste sentido podemos inferir que o padrão de utilização de conchas de $P$. tortugae pode estar fortemente associado à disponibilidade de conchas, ao tamanho e à condição reprodutiva dos indivíduos. 
This study characterized the pattern of shell utilization by the hermit crab Paguristes tortugae, inhabiting infralittoral areas of Anchieta Island (Ubatuba), analyzing comparatively the pattern of the shell occupation in the field and in the laboratory.

For the shell occupation study in the field, the individuals were collected monthly (January to December/1998), by scuba methods in four infralittoral areas of the Island. The hermit crabs were measured on the basis of shield width and length, propodus height and length, sexed and weighed. In the shells selection experiments, the animals were maintained alive in the laboratory. All experiments were conducted in a glass aquarium where the hermit crabs were placed naked with a large number of shells of appropriate sizes. After $72 \mathrm{~h}$ the hermit crabs and chosen shells were analyzed by preference and measured. The shell type preference was estimated by the percentage of occupation of the chosen species. The preferred shell type and size were determined by regression analysis.

A total of 2429 individuals of $P$. tortugae were analyzed (1092 males, 495 non-ovigerous females and 842 ovigerous females), occupying 21 species of gastropod shells characterizing a considerable diversity in the shell occupation pattern. The most occupied shells were Pisania auritula (35.49\%), Cerithium atratum (27.83\%) and Morula nodulosa (12.70\%). The males (38.46\%) and the ovigerous females (38.00\%) occupied in higher percentage $P$. auritula shells, while the non-ovigerous females (39.40\%) occupied C. atratum. It was verified sexual size dimorphism, being the males larger than females. The sex ratio was 1:1.2 in favor of females. It was verified that the most occupied shells least adequate and that $L$. nassa was the most adequate in the field and in the laboratory, corroborating the hypothesis that the shell utilization is associated to the habitat and to the availability in the field. The highest correlation coefficients were obtained for the relations between the crab dimensions and shell dry weight. In relation to sex, the ovigerous females showed the best correlation coefficients being more adequate to the shell weight and internal volume, that may favor the fecundity and the annual 
reproductive process. This condition was corroborated by the laboratory experiments when the ovigerous females preferred shells with higher internal volume (L. nassa e C. atratum). In laboratory, among the six most occupied shell species in the field, the preference pattern was $L$. nassa $>P$. auritula $>S$. haemastoma $>T$. viridula to larger individuals and $C$. atratum > M. nodulosa to the small ones. These results, compared to the field study, showed that $P$. tortugae exhibited a pattern of preference for the most available shells in the field, even if they're not the most adequate to the crab dimensions. In this sense we may infer that the shell utilization pattern of $P$. tortugae may be associated to the shell availability and to the size and reproductive conditions of the individuals. 


\subsection{CARACTERIZAÇÃO DOS ANOMURA}

Dentre os crustáceos, a infraordem Anomura, representada por mais de 1400 espécies, sendo mais de 800 dessas representadas pelos ermitões (HAZLETT, 1981), apresenta-se constituída por um grupo variado de formas, sendo algumas semelhantes a caranguejos (RIEGER, 1999). No entanto, os anomuros têm em comum o $5^{\circ}$ par de pereiópodos reduzido e, em alguns casos, localizados sob a carapaça ou dirigido para o dorso (MELO, 1999).

Entre os Anomura, são reconhecidas quatro superfamílias: Galatheoidea, Lomoidea, Hippoidea e Paguroidea (McLAUGHLIN, 1983; McLAUGHLIN \& LEMAITRE, 1997). Esta última é composta por seis famílias e seus representantes são totalmente distintos em relação à forma (BERTINI, 1997), englobando representantes das famílias: Coenobitidae, Diogenidae, Paguridae, Parapaguridae, Pomatochelidae (=Pylochelidae) e Lithodidae (McLAUGHLIN, 1983). Dessas, somente Coenobitidae não ocorre na costa brasileira (MELO, 1999).

A separação entre Diogenidae e Paguridae representou a maior divisão na evolução dos Anomura, pois cada um destes grupos seguiu linhas independentes no que se referiu ao modo de utilização de conchas (McLAUGHLIN, 1983; BERTINI, 1997).

Os ermitões, conhecidos popularmente como caranguejo-da-concha, caranguejo-ermitão, caranguejo-eremita ou simplesmente ermitão (HEBLING \& RIEGER, 1986), são crustáceos que se adaptaram à ocupação de conchas vazias de moluscos gastrópodos, condição esta adquirida frente à ausência de calcificação do exoesqueleto abdominal (HAZLETT, 1981; OHMORI et al., 1995). Habitam desde os mares polares até o tropicais e as regiões supratidais até as abissais (McLAUGHLiN, 1983), sendo encontrados em estuários, baías e enseadas (GARCIA, 2000).

As espécies de ermitões registradas mundialmente (HAZLETT, 1981), encontram-se distribuídas em 86 gêneros e seis famílias, sendo 
somente 12 espécies semi-terrestres e as demais marinhas (McLAUGHLIN, 1983).

No Brasil existem 46 espécies de ermitões registradas, sendo 23 pertencentes à família Diogenidae, distribuídas em oito gêneros, 20 pertencentes à família Paguridae, distribuídas em nove gêneros e três pertencentes à familia Parapaguridae, com um gênero apenas (MELO, 1999).

No litoral do Estado de São Paulo, foram registradas 20 espécies de ermitões (MELO, 1999), sendo 13 de Diogenidae e sete de Paguridae. Recentemente foi registrado o diogenideo Dardanus venosus (H. Milne Edwards, 1848), aumentando para 21 espécies, totalizando 14 de Diogenidae encontradas no litoral paulista (MANTELATTO et al., 2001), a saber: Calcinus tibicen (Herbst, 1791), Clibanarius antillensis (Stimpson, 1859), Clibanarius sclopetarius (Herbst, 1796), Clibanarius vittatus (Bosc, 1802), Dardanus insignis (de Saussure, 1858), Dardanus venosus (H. Milne Edwards, 1848), Isocheles sawayai (Forest \& Saint Laurent, 1967), Loxopagurus loxochelis (Moreira, 1901), Paguristes calliopsis Forest \& Saint Laurent, 1967, Paguristes erythrops Holthuis, 1959, Paguristes pauciparus Forest \& Saint Laurent, 1967, Paguristes puncticeps Benedict, 1901, Paguristes tortugae Schmitt, 1933 e Petrochirus diogenes (Linnaeus, 1758).

A família Diogenidae, a qual pertence a espécie do presente estudo, apresenta os $3^{\circ}$ maxilipedes próximos à base e possuem 14 pares de brânquias (HEBLING \& RIEGER, 1986), sendo que o gênero Paguristes possui os pleópodos pares (MELO, 1999). Com exceção à Paguristes anomalus Bouvier, 1918 (McLAUGHLIN \& PROVENZANO, 1974), todas as fêmeas desse gênero apresentam uma bolsa incubadora (HEBLING \& RIEGER, 1986), características essas que os diferem dos demais gêneros da família Diogenidae. 


\subsection{RELAC̣ÃO COM A CONCHA}

Os ermitões ocupam e carregam as conchas como proteção, muito em parte favorecida pela torção do abdomen associada à presença dos urópodos modificados, possibilitando ao animal prender-se à columela das conchas.

A forte associação entre os ermitões e seu abrigo adotado, tem influenciado fortemente quase todos os aspectos de sua biologia (HAZLETT, 1981), sendo o uso da concha uma das principais razões de seu sucesso evolutivo (CONOVER, 1978).

Considerando-se o grande número de ermitões existentes, são poucos os estudos realizados sobre a relação entre o ermitão e as conchas utilizadas, o que vem reforçar a necessidade de um melhor entendimento sobre tais aspectos (OHMORI et al., 1995). Dentre esses trabalhos, destacam-se alguns em nivel mundial, que estão relacionados diretamente aos padrões de utilização das conchas: FOTHERINGHAM (1976a), estudou a razão de crescimento da espécie Pagurus longicarpus Say, 1817 e Pagurus pollicaris Say, 1817 em conchas adequadas e inadequadas; BERTNESS (1980; 1982) estudou a preferência por conchas das espécies Calcinus obscurus (Stimpson, 1862), Clibanarius albidigitus (Nobili, 1901) e Pagurus sp.; ASAKURA \& KIKUCHI (1984), verificaram a dinâmica populacional e a utilização de conchas pelos ermitões Diogenes nitidimanus Terao, 1913; SIU \& LEE (1992) verificaram os padrões de preferência e de utilização de conchas em Pagurus trigonocheirus (Stimpson, 1858) e Clibanarius bimaculatus (De Haan, 1849); OHMORI et al. (1995), estudaram a disponibilidade de conchas e seus padrões de utilização pelo ermitão Pagurus filholi (De Man, 1887); MANJÓN-CABEZA \& GARCÍA-RASO (1999) estudaram a utilização de conchas de Diogenes pugilator (Roux, 1829), Paguristes eremita (Linnaeus, 1767) e Pagurus forbesii Bell, 1845 e SHIH \& MOK (2000) estudaram a utilização de conchas de Calcinus latens (Randall, 1840) e Calcinus gaimardii (H. Milne Edwards, 1848). 
Poucos estudos sobre a relação ermitão/concha foram realizados para a costa brasileira, destacando-se os trabalhos efetuados no litoral norte do Estado de São Paulo. São eles: NEGREIROS-FRANSOZO et al. (1991), analisaram a estrutura populacional e a determinação do tamanho da concha em Pagurus criniticornis (Dana, 1852), Pagurus brevidactylus (Stimpson, 1859), C. vittatus e C. antillensis; NEGREIROSFRANSOZO \& FRANSOZO (1992), estudaram a estrutura populacional e a relação com a concha Stramonita haemastoma em $P$. tortugae; PINHEIRO et al. (1993), estudaram a seleção e a relação com conchas de gastrópodos para I. sawayai; ARANTES (1994), verificou a utilização de conchas pelos gêneros Clibanarius e Pagurus; FERNANDES-GÓES (1997), verificou a distribuição e a biologia populacional de $D$. insignis; REIGADA \& SANTOS (1997), estudaram a relação com a concha em $C$. vittatus, TURRA (1998), estudou o modo de vida de três espécies simpátricas do gênero Clibanarius verificando também os padrões de utilização de conchas dessa população; MARTINELLI \& MANTELATTO (1999), analisaram as conchas utilizadas por L. loxochelis; BERTINI \& FRANSOZO (2000), estudaram o padrão de utilização de conchas em $P$. diogenes e MANTELATTO \& GARCIA (2000), caracterizaram o padrão das conchas utilizadas por C. tibicen.

Estudos sobre a ecologia e a evolução dos ermitões têm sido enfocados sobre as conseqüências frente ao limitado número de conchas disponiveis no ambiente, bem como do tipo (características) do recurso disponivel (CARLON \& EBERSOLE, 1995). Tal limitação pode trazer conseqüências no tamanho da população e na fecundidade (FOTHERINGHAM, 1976b) destes ermitões. A adequação dos ermitões às conchas disponiveis no ambiente em que vivem envolve uma série de fatores, dentre os quais destacam-se alguns, tais como as características morfométricas.

Outro aspecto decisivo diz respeito à relação entre o tamanho da concha e o tamanho do animal, cuja escolha muitas vezes pode ser limitada pela diversidade de conchas existentes. Fatores como estes podem levar a novas conseqüências na utilização de conchas, como por 
exemplo a presença de conchas pequenas, que pode levar o ermitão a percorrer distâncias maiores em busca de conchas vazias ou para troca destas com outros animais (HAZLETT, 1981). Provavelmente esta condição seja um dos fatores responsáveis pelo fato de que um número reduzido de indivíduos de uma determinada população, sejam encontrados em conchas adequadas (VANCE, 1972a).

A biologia dos gastrópodos constitui um fator fundamental para os ermitões. Seguramente a ocupação de conchas por estes crustáceos no ambiente natural depende da abundância de moluscos vivos no local (SPIGHT, 1985; MANTELATTO \& GARCIA, 2000), dos tipos e dos tamanhos de conchas disponiveis (OHMORI et al., 1995), além da mortalidade destes gastrópodos, já que os ermitões em condições naturais normalmente não os predam (RUTHERFORD, 1977; SHIH \& MOK, 2000), mas possivelmente sejam atraídos por um sinal químico liberado pelos moluscos mortos (WILBER \& HERRNKIND, 1982).

A competição intra e interespecífica para a troca e a aquisição de conchas constituem um dos aspectos importantes e decisivos (HAZLETT, 1981), uma vez que são um dos responsáveis pela incorporação de novos recursos (conchas) em uma área de ocupação (GARCIA, 2000).

Os ermitões não ocupam as conchas vazias de gastrópodos sem antes analisá-las (CONOVER, 1978). Normalmente, observa-se um mecanismo de "análise" prévio do animal sobre a concha, onde os quelipodos giram estas e exploram a abertura e o espaço interno antes da efetiva ocupação (BERTINI \& FRANSOZO, 2000). De acordo com REESE (1962), os ermitões podem diferenciar entre conchas de várias espécies e também reconhecer uma ocupação anterior. Podem ainda discriminar o peso entre conchas da mesma espécie, sua forma, cobertura e dimensão, possivelmente selecionando conchas adequadas ao seu próprio peso (MARTINELLI, 1998).

Os ermitões, à medida em que crescem, precisam de conchas cada vez maiores (FOTHERINGHAM, 1976b; BERTNESS, 1981a), o que os torna em constante atividade de busca por conchas adequadas, seja 
esta para melhor adequação ao tamanho real ou "prevendo" o seu crescimento futuro (HAZLETT, 1992). Segundo HAZLETT \& HERRNKIND (1980), algumas espécies não selecionam as conchas quanto à sua utilização, ocupando as mais facilmente encontradas no ambiente, enquanto que outros autores, tais como CONOVER (1978), GHERARDI (1990) e MESCE (1993), afirmam que outras espécies selecionam conchas constantemente, embora este grau de seleção esteja relacionado à disponibilidade local de conchas.

O estudo da ocupação de conchas de gastrópodos pelos ermitões, no habitat natural, é escasso devido às dificuldades para o delineamento experimental (MANJON-CABEZA \& GARCÍA-RASO, 1999). Todavia, este tipo de análise proporciona uma visão mais ampla sobre o comportamento real das espécies em seus ambientes naturais e suas reações sob diferentes condições (GHERARDI, 1991).

Observações diretas são basicamente realizadas com espécies intertidais, descrevendo-se competições intra e interespecíficas para a disponibilidade de conchas de gastrópodos nesse ambiente, enquanto que experimentos em laboratório são utilizados para a compreensão da adequação de tamanho entre concha e ermitão (OHMORI et al., 1995), confrontando-se em seguida o resultado de ambos.

Alguns trabalhos demonstraram que os ermitões ocupam conchas inadequadas (GHERARDI, 1990). Esta ocupação ocorre em função da escassez ou do estado geral das conchas disponiveis. Tais condições podem ser desfavoráveis, visto que os ermitões precisam ocupar sucessivamente conchas durante seu ciclo de vida. Apesar deste perfil, algumas espécies ocupam conchas adequadas no ambiente em que vivem (BERTNESS, 1980; MANTELATTO \& GARCIA, 2000). 


\section{OBJETIVOS}


Este trabalho teve como objetivo a caracterização da ocupação das conchas de gastrópodos pelo ermitão Paguristes tortugae, habitante do infralitoral do Parque Estadual da Ilha Anchieta, Ubatuba (SP). Neste aspecto, o padrão de ocupação na natureza e no laboratório, foi caracterizado para machos, fêmeas não-ovígeras e fêmeas ovígeras, investigando-se a hipótese sobre a ocupação pelo tipo (espécie) e pelo tamanho das conchas ser um caráter da espécie associado à disponibilidade dos recursos. 


\subsection{CARACTERIZAÇÃO DA ESPÉCIE EM ESTUDO}

A espécie Paguristes tortugae (Figura 1), descrita por SCHMITT em 1933, na Flórida (McLAUGHLIN \& PROVENZANO, 1974), se caracteriza por possuir os quelipodos iguais, com as extremidades dos dedos alargadas e córneas (MELO, 1999), podendo ser diferenciada das demais espécies do gênero por possuir anéis pretos nos pedúnculos oculares, antenulares e antenais, em número, tamanho e posição constantes (NEGREIROS-FRANSOZO \& FRANSOZO, 1992).

São encontrados na zona entre-marés, sob rochas e em fundos de areia, lama e algas calcárias, em profundidades de até 55 metros. Sua ocorrência restringe-se ao Atlântico Ocidental - Carolina do Norte, Flórida, Golfo do México, América Central, Antilhas, Suriname e Brasil (Pará, Pernambuco, Bahia, Rio de Janeiro, São Paulo e Santa Catarina) (RIEGER \& GIRALDI, 1997; MELO, 1999).

São poucos os estudos realizados com esta espécie. Entre eles foram abordados alguns aspectos de sua biologia, como o desenvolvimento pós-embrionário (HEBLING \& NEGREIROS-FRANSOZO, 1983), a estrutura populacional e as conchas ocupadas (NEGREIROSFRANSOZO \& FRANSOZO, 1992), a fecundidade (NEGREIROSFRANSOZO et al., 1992), o padrão de utilização de conchas associado aos aspectos da reprodução (GANDOLFI, 1996), a biologia populacional e a razão sexual (MANTELATTO \& SOUSA, submetido; SOUSA \& MANTELATTO, 2000) e a caracterização do potencial reprodutivo associado às conchas (MANTELATTO et al, submetido).

Paguristes tortugae é uma espécie encontrada em grande número no litoral paulista, sendo que na área do presente estudo foi a mais abundante dentre as espécies viventes no local (MANTELATTO \& GARCIA, no prelo). 


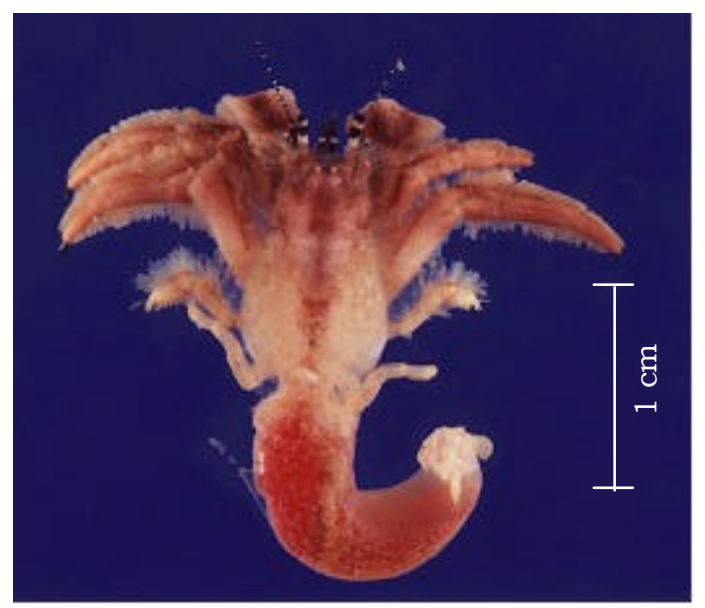

Figura 1: P. tortugae. Foto de uma fêmea adulta (vista dorsal) de $P$. tortugae.

\subsection{CARACTERIZAÇÃO DA ÁREA DE ESTUDO}

De acordo com os estudos de AB'SABER (1955) e de SUGUIO \& MARTIN (1978), a geomorfologia da costa norte do Estado de São Paulo é caracterizada por um litoral recortado, com enseadas, baías e ilhas oceânicas. Neste contexto, encontra-se o Parque Estadual Marinho da Ilha Anchieta $\left(23^{\circ} 35^{\prime} \mathrm{S}-45^{\circ} 05^{\prime} \mathrm{W}\right)$, localizado no município de Ubatuba, a leste da entrada da Baía do Flamengo.

Esta ilha é considerada a segunda maior do litoral paulista (cerca de $10 \mathrm{Km}^{2}$ ). Está separada do continente por um canal de aproximadamente 300 metros de largura com profundidade de 35 metros (OLIVEIRA, 1983). Caracteriza-se por apresentar um paredão rochoso irregular e um fundo sublitoral não-consolidado constituído de cascalho e areia grossa, com uma profundidade de aproximadamente nove metros (MANTELATTO et al., 2001).

A região de Ubatuba constitui uma importante zona de transição faunística entre a Patagônia e regiões tropicais (MANTELATTO, 1995), com conjuntos de organismos adaptados às condições flutuantes do meio, havendo proporção significativa de elementos endêmicos, alguns membros das faunas adjacentes (Caribe e Patagônia) e organismos circuntropicais (MEDEIROS, 1989). 
Segundo PALÁCIO (1982), na região de Ubatuba, onde a plataforma continental é mais ampla, as temperaturas da água são maiores durante fevereiro e menores nos meses de agosto e setembro. As salinidades variam devido ao influxo de águas costeiras do fundo e à precipitação, com valores de picos anuais e semianuais.

\subsection{METODOLOGIA DE COLETA}

As coletas diurnas foram efetuadas mensalmente no período de janeiro a dezembro/1998, na região infralitorânea de quatro áreas da Ilha Anchieta, localizadas nas Praias do Leste, Prainha, Saco do Vento e Praia do Sul (Figura 2).

Um estudo recente sobre a estrutura populacional de $P$. tortugae nesses 4 pontos de coleta (SOUSA, 2000), evidenciou populações com estruturas semelhantes, sem diferenças significativas no seu perfil. Desta forma optou-se por agrupar os individuos coletados nestes 4 pontos no presente trabalho, analisando-os como uma única população.

As amostragens foram realizadas por mergulho autônomo, com um esforço de captura total dos animais, delimitado por três mergulhadores, num período de 30 minutos por área, abrangendo aproximadamente o total de $850 \mathrm{~m}^{2}$. As coletas foram efetuadas no mesmo dia, em duas áreas da Ilha para cada mês, respeitando-se as condições do mar, acesso seguro por barco e boa visibilidade da água para a realização dos mergulhos. Nos meses de janeiro, julho e setembro, apenas uma área foi amostrada devido às más condições para o mergulho.

Os animais coletados foram colocados em sacos de coleta, levados até o barco e colocados em isopor com água local. No laboratório foram colocados em sacos plásticos, etiquetados e congelados em freezer até o momento das análises.

Durante o estudo foi realizado o monitoramento de alguns fatores físico-químicos. A profundidade e a temperatura foram medidas pelo manômetro do equipamento de mergulho e a salinidade mensurada por 
um refratômetro, visando determinar uma possível associação entre esses fatores (salinidade e temperatura) com o número de indivíduos obtidos, utilizando-se o teste de Correlação de Pearson $(\mathrm{p}<0.05)$.

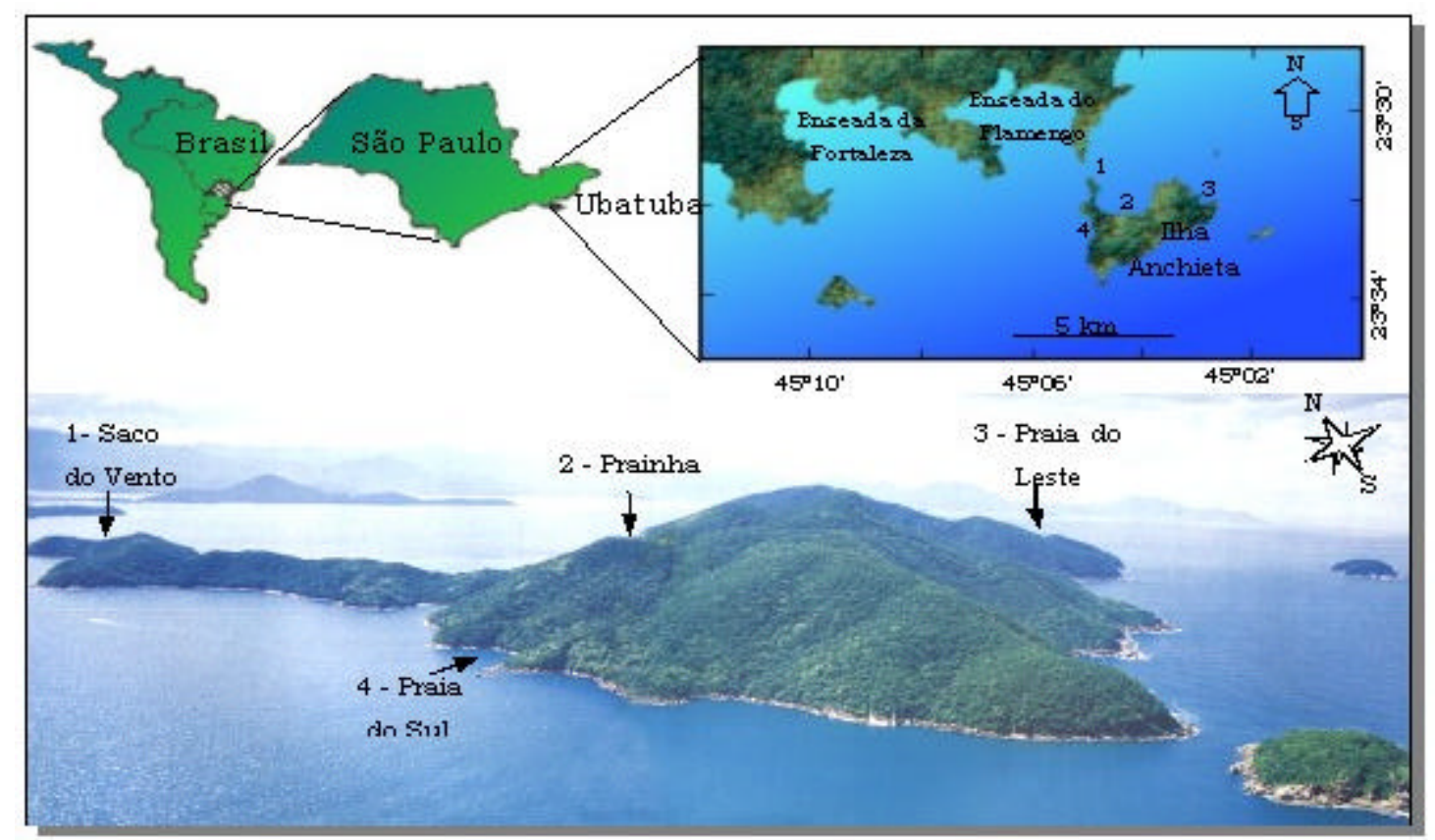

Figura 2: Vista aérea da Ilha Anchieta com seus respectivos pontos de coleta (retirado de MANTELATTO, 2000).

\subsection{ASPECTOS ANALISADOS}

As observações e análises laboratoriais foram efetuadas no laboratório de Bioecologia de Crustáceos do Departamento de Biologia da Faculdade de Filosofia, Ciências e Letras de Ribeirão Preto, da Universidade de São Paulo. 


\subsubsection{ERMITÕES}

Os ermitões foram identificados e caracterizados com base nos trabalhos de FOREST \& SAINT LAURENT (1967), HEBLING \& RIEGER (1986), NEGREIROS-FRANSOZO \& FRANSOZO (1992) E MELO (1999).

Após o descongelamento à temperatura ambiente, os ermitões foram retirados manualmente de suas conchas, ou quando necessário, quebrando-as com uma morsa. Em seguida foram contados, pesados a fresco em balança eletrônica $(0.01 \mathrm{~g})$ e feita a determinação do sexo considerando-se a posição dos gonóporos (Figura 3-A) (fêmeas: localizados na base do $3^{\circ}$ par de pereiópodos; machos: localizados na base do $5^{\circ}$ par de pereiópodos).

Foram efetuadas as medidas do Comprimento (CEC) e da Largura do Escudo Cefalotorácico (LEC) (Figura 3-B), do Comprimento (CPQ) e da Altura do Própodo Quelar (APQ) (Figura 3-C), com um paquímetro de precisão $(0.01 \mathrm{~mm})$ e, quando necessário, sob estereomicroscópio provido de câmara clara.

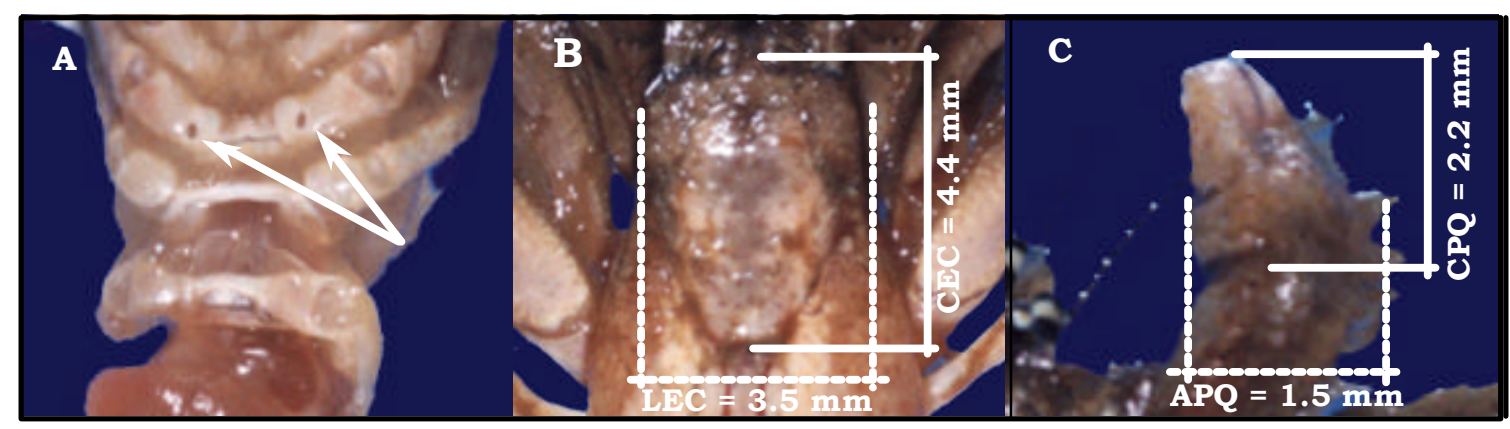

Figura 3: P. tortugae. Dimensões utilizadas nas análises. (A) Poros genitais femininos indicados pela flecha; (B) LEC = Largura do Escudo Cefalotorácico; $\mathrm{CEC}=$ Comprimento do Escudo Cefalotorácico; $(\mathrm{C}) \mathrm{APQ}=$ Altura do Própodo Quelar; $\mathrm{CPQ}=$ Comprimento do Própodo Quelar. 


\subsubsection{CONCHAS}

Para as conchas foram mensurados o peso seco (24 horas em estufa à $60^{\circ} \mathrm{C}$ ) em balança eletrônica $(0.01 \mathrm{~g})$ e a Largura (LAC) e o Comprimento de Abertura da Concha (CAC) (Figura 4), com um paquímetro de precisão $(0.01 \mathrm{~mm})$. Para a determinação do Volume Interno da Concha (VIC), procedeu-se o preenchimento das conchas com areia fina $(\varnothing=0.25-0.105 \mathrm{~mm})$, determinando-se o volume deslocado pela areia em uma proveta graduada $\left(0.01 \mathrm{~mm}^{3}\right)($ BERTNESS, 1981d; GARCIA, 2000).

As conchas ocupadas foram identificadas com base no trabalho de RIOS (1994) e quando necessária, a identificação dos exemplares foi realizada pelo Prof. Dr. Osmar Domaneschi (IB/USP-São Paulo).

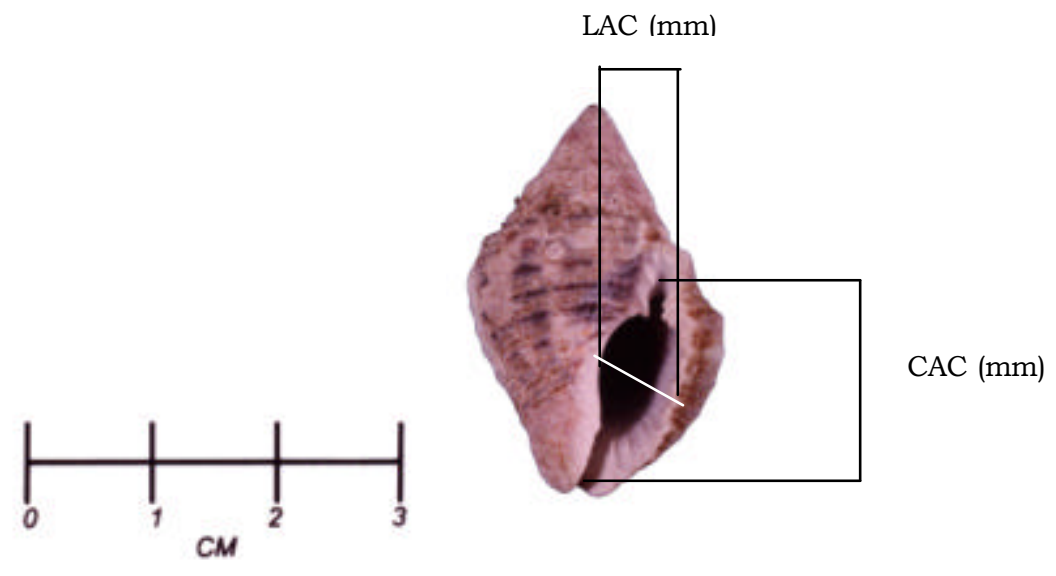

Figura 4: Exemplar da espécie de concha Pisania auritula. Medidas amostradas, $\mathrm{CAC}=$ Comprimento de Abertura da Concha e LAC = Largura de Abertura da Concha.

\subsection{OCUPAÇÃO DAS CONCHAS}

As relações entre os parâmetros das conchas ocupadas com o tamanho do ermitão, foram verificadas por análise de regressão adotando-se a equação do tipo função potência $\mathrm{Y}=\mathrm{aX} \mathrm{X}^{\mathrm{b}}(\mathrm{Y}=$ dimensões 
da concha; $\mathrm{X}=$ medidas dos ermitões; $\mathrm{a}=$ índice de origem; $\mathrm{b}=$ crescimento alométrico ou constante de equilíbrio).

Para verificar as diferenças quanto ao tamanho das conchas e a ocupação por machos, fêmeas não-ovígeras e fêmeas ovigeras, utilizouse o teste ANOVA on Ranks (Kruskal-Wallis One Way Analysis on Ranks) e, para verificar as diferenças entre a porcentagem de ocupação de uma espécie de concha em relação à outra, utilizou-se o teste do $\chi^{2}$.

Para a distribuição da população foi utilizado o teste de Normalidade de Kolmogorov-Smirnov (ZAR, 1996). O nivel de significância utilizado em todos os testes foi de $\mathrm{p}<0.05$.

\subsection{SELEÇÃO DAS CONCHAS EM LABORATÓRIO}

Após o conhecimento e a identificação prévia de conchas utilizadas pelos ermitões no ambiente, procederam-se os estudos em laboratório sobre a seleção de conchas. Para comparar a ocupação de conchas no ambiente com as selecionadas experimentalmente, seguiu-se a metodologia de GARCIA (2000). Nesta etapa foram utilizadas apenas as conchas que se encontravam em bom estado (inteiras, sem buracos ou incrustações).

Os ermitões foram coletados nas mesmas áreas da Ilha Anchieta, adotando-se a mesma metodologia descrita no estudo de ocupação das conchas. Porém, as coletas para este estudo foram efetuadas em períodos alternados entre fevereiro/2000 e março/2001. Os animais coletados foram transportados para o laboratório e mantidos vivos em aquários de vidro (30 x 30 × 40cm), mantidos com água do mar do local de coleta, filtro biológico e fundo de cascalho, por um período de 40 dias para adaptação.

Cada animal foi utilizado apenas uma vez nos experimentos para que os resultados fossem independentes de algum comportamento adquirido. Após o término dos experimentos, esses animais foram 
devolvidos para o ambiente natural. Quanto ao sexo, os ermitões foram selecionados aleatoriamente.

\subsubsection{SELEÇÃO DO TIPO DE CONCHA}

Foram utilizadas as espécies de conchas mais ocupadas na área de estudo. Os testes foram efetuados em etapas, sendo oferecidas simultaneamente duas espécies de conchas (de tamanhos variados, apropriadas ao tamanho dos ermitões e semelhantes quanto ao peso).

Os ermitões foram retirados de suas conchas quebrando-as com uma morsa. Após um breve repouso em recipientes individuais, foram colocados no aquário onde se encontravam as conchas a serem escolhidas. Estas foram previamente distribuidas uniformemente no fundo dos aquários. Após um período de 72 horas (tempo de escolha testado previamente), os ermitões foram removidos das conchas escolhidas (aquecendo-se a concha com água quente - GARCIA, 2000), medidos quanto ao Comprimento do Escudo Cefalotorácico (CEC), pesados a fresco (PUE) e feita a determinação do sexo. Para as conchas determinou-se a Largura (LAC) e o Comprimento (CAC) de Abertura, o Peso Seco (PSC), após permanecer em estufa por 24 horas a $60^{\circ} \mathrm{C}$ e o seu Volume Interno (VIC).

Para cada experimento foram efetuadas quatro réplicas inteiramente casualizadas, as quais foram oferecidas duas espécies de conchas. Para cada réplica, utilizou-se 15 ermitões e 75 conchas de cada espécie. Os animais que morreram durante os experimentos foram excluídos dos resultados.

A análise de seleção das espécies de conchas foi averiguada em função da maior porcentagem de ocupação de uma espécie em relação à outra (teste $\left.\chi^{2} ; \mathrm{p}<0.05\right)$, bem como por meio da significância $(\mathrm{p}<0.05)$ do coeficiente de correlação (r) obtidos a partir das análises de regressão (adotando-se a equação do tipo função potência $\mathrm{Y}=\mathrm{aX}{ }^{\mathrm{b}}$ ) entre as dimensões dos ermitões e das conchas escolhidas. 


\subsubsection{SELEÇÃO DO TAMANHO DA CONCHA}

Para determinação da preferência por um tamanho específico de concha foram utilizadas as espécies mais ocupadas pelos ermitões no ambiente.

Em cada teste, foram oferecidos aos ermitões ( $n=15)$ um número considerável de conchas da mesma espécie $(\mathrm{n}=150)$ de tamanhos variados e passiveis de utilização, tomando-se o cuidado de fornecer conchas com tamanhos semelhantes aos da natureza. Após 72 horas os ermitões foram removidos das conchas escolhidas, medidos quanto ao Comprimento do Escudo Cefalotorácico (CEC) e pesados a fresco (PUE). As conchas foram medidas quanto à Largura (LAC) e ao Comprimento de Abertura (CAC), pesadas a seco (PSC) (24 horas em estufa a $60^{\circ} \mathrm{C}$ ) e feito o seu Volume Interno (VIC).

Foram efetuadas quatro réplicas ( $\mathrm{n}$ total $=60$ individuos) inteiramente casualizadas do experimento para cada espécie de concha, escolhidos aleatoriamente quanto ao sexo, sendo descartados das análises os animais que morreram durante a realização dos experimentos.

Análises de regressão (adotando-se a equação do tipo função potência $\mathrm{Y}=\mathrm{aX} \mathrm{X}^{\mathrm{b}}$ ) foram efetuadas para as relações entre as dimensões dos ermitões e as variáveis das conchas. Foram estabelecidas as equações que refletiram o tipo e o tamanho de concha mais adequados aos ermitões da espécie em estudo, estabelecidas pela análise da significância do coeficiente de correlação $(r)(p<0.05)$. 